\title{
Differences in LC3B expression and prognostic implications in oropharyngeal and oral cavity squamous cell carcinoma patients
}

Kenneth Lai ${ }^{1,2,3,4,10^{*}}$, Slade Matthews ${ }^{1,5}$, James S. Wilmott ${ }^{1,6}$, Murray C. Killingsworth ${ }^{2,3,4,7}$, Jim L. Yong ${ }^{4}$, Nicole J. Caixeiro ${ }^{2,3}$, James Wykes ${ }^{7,8}$, Allan Samakeh ${ }^{8}$, Dion Forstner ${ }^{7,9}$, Mark Lee ${ }^{9}$, John McGuinness ${ }^{8}$, Navin Niles ${ }^{8}$, Angela Hong ${ }^{1}$, Ardalan Ebrahimi ${ }^{8}$ and Cheok Soon Lee Le, $^{1,3,4}$

\begin{abstract}
Background: This study examined the prognostic significance of microtubule-associated protein light chain 3B (LC3B) expression in oropharyngeal and oral cavity squamous cell carcinoma (SCC). The prognostic significance of LC3B expression in relation to human papillomavirus (HPV) status in oropharyngeal SCC was also examined.

Methods: Tissue microarrays (TMAs) were constructed from formalin-fixed, paraffin-embedded oropharyngeal $(n=47)$ and oral cavity $(n=95)$ SCC tissue blocks from patients with long-term recurrence and overall survival data (median $=47$ months). LC3B expression on tumour was assessed by immunohistochemistry and evaluated for associations with clinicopathological variables. LC3B expression was stratified into high and low expression cohorts using ROC curves with Manhattan distance minimisation, followed by Kaplan-Meier and multivariable survival analyses. Interaction terms between HPV status and LC3B expression in oropharyngeal SCC patients were also examined by joint-effects and stratified analyses.
\end{abstract}

Results: Kaplan-Meier survival and univariate analyses revealed that high LC3B expression was correlated with poor overall survival in oropharyngeal SCC patients ( $p=0.007$ and $\mathrm{HR}=3.18,95 \% \mathrm{Cl} 1.31-7.71, p=0.01$ respectively). High LC3B expression was also an independent prognostic factor for poor overall survival in oropharyngeal SCC patients $(H R=4.02,95 \% \mathrm{Cl} 1.38-11.47, p=0.011)$. In contrast, in oral cavity SCC, only disease-free survival remained statistically significant after univariate analysis ( $\mathrm{HR}=2.36,95 \% \mathrm{Cl} 1.19-4.67, p=0.014)$, although Kaplan-Meier survival analysis showed that high LC3B expression correlated with poor overall and disease-free survival ( $p=0.046$ and 0.011 respectively). Furthermore, oropharyngeal SCC patients with HPV-negative/high LC3B expression were correlated with poor overall survival in both joint-effects and stratified presentations ( $p=0.024$ and 0.032 respectively).

(Continued on next page)

\footnotetext{
* Correspondence: k.lai@uws.edu.au

${ }^{1}$ Sydney Medical School, The University of Sydney, Sydney, Australia

${ }^{2}$ Discipline of Pathology, School of Medicine, Western Sydney University,

Sydney, Australia

Full list of author information is available at the end of the article
}

(c) The Author(s). 2018 Open Access This article is distributed under the terms of the Creative Commons Attribution 4.0 International License (http://creativecommons.org/licenses/by/4.0/), which permits unrestricted use, distribution, and reproduction in any medium, provided you give appropriate credit to the original author(s) and the source, provide a link to the Creative Commons license, and indicate if changes were made. The Creative Commons Public Domain Dedication waiver (http://creativecommons.org/publicdomain/zero/1.0/) applies to the data made available in this article, unless otherwise stated. 


\begin{abstract}
(Continued from previous page)
Conclusions: High LC3B expression correlates with poor prognosis in oropharyngeal and oral cavity SCC, which highlights the importance of autophagy in these malignancies. High LC3B expression appears to be an independent prognostic marker for oropharyngeal SCC but not for oral cavity SCC patients. The difference in the prognostic significance of LC3B between oropharyngeal and oral cavity SCCS further supports the biological differences between these malignancies. The possibility that oropharyngeal SCC patients with negative HPV status and high LC3B expression were at particular risk of a poor outcome warrants further investigation in prospective studies with larger numbers.
\end{abstract}

Keywords: Autophagy, LC3B, Oropharyngeal, Oral cavity, SCC, HPV, Immunohistochemistry, Survival outcome,

\section{Background}

Oropharyngeal and oral cavity squamous cell carcinoma (SCC) make up the majority of head and neck cancers and combined, rank as the eighth most common cancer worldwide [1, 2]. The incidence of oropharyngeal SCC has increased substantially in developed countries over the past few decades while the incidence of oral cavity SCC has remained stable or even decreased [3-10]. Although oropharyngeal and oral cavity SCC are often collectively studied as "oral SCC" as well as aggregated with other head and neck cancers, these malignancies are distinctively different from one another including the impact of human papillomavirus (HPV) infection, biology and treatment approaches [11]. HPV positive oropharyngeal SCC patients tend to display a better survival outcome in comparison to HPV negative patients [12-14]. In contrast, the clinical significance of HPV infection in oral cavity SCC is ambiguous. [15-23].

Macroautophagy (referred to as autophagy hereafter) is a process of cellular self-consumption for recycling of intracellular components and has recently received much interest in cancer therapeutic research due to its unique role in both pro- and anti-cancer activity [24]. Autophagy begins with the formation of a phagophore that can be either generated by de novo formation or from various cellular components including the plasma membrane, Golgi apparatus, endoplasmic reticulum and outer mitochondrial membrane [25]. During autophagy induction, intracellular components are sequestered by phagophores and develop into autophagosomes that fuse with lysosomes, mature into autolysosomes for degradation and generate into amino acids for biomass and/or energy production [24]. Autophagy can be either non-selectively targeting cytoplasm for bulk degradation or selectively targeting cellular components including aggregated proteins and damaged organelles [26]. Autophagy helps to maintain cellular homoeostasis but it can also be upregulated in response to various stresses including pathogen invasion, cytotoxicity, oxygen and nutrient deprivation [26]. Furthermore, imbalance of autophagy is associated with numerous diseases such as systemic lupus erythematosus, Crohn's disease and cancers [27].
The role of autophagy in cancer progression remains controversial due to its possession of both pro- and anti-cancer properties [28]. On the pro-cancer side, autophagy provides amino acids as an alternative energy source for cancer cell proliferation as well as generates resistance toward radiotherapy and chemotherapy. On the other hand, autophagy can also lead to type II programmed cell death [24]. Regarding therapeutic uses, autophagy inhibitors are shown to increase the potency of various chemotherapy agents in cancers. Clinical trials investigating the effectiveness of autophagy inhibitors in combination with immunotherapy, targeted therapy, and chemotherapy in cancers have been launched since 2010 and display encouraging preliminary results [29]. Recently, nanomedicine that involves a polymeric co-delivery system, allowing the sequential release of the autophagy inhibitor, LY294002, and a chemotherapeutic agent, doxorubicin, displayed promising results in the oral cavity (tongue) SCC cell lines [30].

Microtubule-associated protein light chains 3 (LC3) is a specific autophagosome marker and has been demonstrated to be an effective prognostic marker in various cancers including oral SCC [31, 32]. LC3 participates in autophagosome membrane elongation, and its activated form binds tightly to the pre-autophagosomal, autophagosomal and autolysosomal membranes [24, 33, 34]. LC3 consists of three main members, which include LC3A, LC3B and LC3C [35]. Increased expression in LC3A and LC3B correlates with poor prognosis in various cancers including breast cancer, colorectal cancer, gastric cancer and oral SCC [31, 32, 36-40]. LC3C is lesser known, and its prognostic value in cancer remains unclear. Although high LC3B expression has been associated with poor disease-free survival in oral SCC patients [32], some studies incorrectly regard oral SCC as both oropharyngeal and oral cavity SCC [11]. As oropharyngeal and oral cavity SCC are distinctive SCC subgroups due to their different biology and management [11], a more definitive LC3B prognostic assessment between these malignancies would help to further establish their association with autophagy activity and thus assess the effectiveness of utilizing autophagy as a therapeutic strategy in oropharyngeal and oral cavity SCC. 
The present study further examines for any difference in LC3B expression between oropharyngeal and oral cavity SCC patients through LC3B immunohistochemistry assessment and correlation with prognosis, clinical and pathological characteristics of patients. The combined effects of HPV and LC3B expression as predictors of outcome in oropharyngeal SCC patients were also examined.

\section{Methods}

\section{Study cohorts}

Patients with T1-4, N0-3, M0 diagnosed between 2000 and 2014 were identified from the database of the NSW Cancer Registry. Department of Anatomical Pathology databases, hospital and surgeon records were used to verify and input missing data as required. Retrieved data was validated by the treating clinicians (JW and AS). Patients with missing and/or incomplete follow up, and treatment records were excluded from the study. Patients were followed up for the occurrence of an event, which was defined as recurrence in any form or death from any cause, for between 2 and 275 (median = 47) months after diagnosis. A total of 142 oropharyngeal $(n=47)$ and oral cavity $(n=95)$ SCC patients were included in the study. The formalin fixed paraffin embedded (FFPE) tissue of the primary tumors, as well as their corresponding hematoxylin and eosin stained (H\&E) slides were obtained from the Department of Anatomical Pathology, Liverpool Hospital, New South Wales, Australia.

\section{Tissue microarray (TMA) construction}

$\mathrm{H} \& \mathrm{E}$ slides were examined by light microscopy and located regions of interest (ROI) including the central and peripheral regions of the tumor as well as lymph node metastases where applicable. Using the H\&E slides as a reference, duplicate tissue cores from each ROI were removed from the FFPE tissue blocks (donor blocks) and inserted into a blank paraffin block (recipient block) using MTA-1 manual tissue arrayer (Beecher Instruments, Sun Prairie, USA). All TMA blocks were sectioned at $3 \mu \mathrm{m}$ thickness and collected on Superfrost plus glass slides (Thermo Fisher Scientific, Waltham, USA) before immunohistochemistry.

\section{Immunohistochemistry}

LC3B immunohistochemistry (IHC) staining was performed manually. All procedures were performed at room temperature unless otherwise specified. All involved reagents were manufactured by Dako, Glostrup, Denmark. Sections were rinsed with EnVision FLEX Wash Buffer after each incubation step until the antibody binding visualisation. Sections were deparaffinised in xylene and rehydrated through graded alcohol. Heat induced antigen retrieval was carried out using EnVision FLEX Target Retrieval Solution High pH for $20 \mathrm{~min}$ at $98^{\circ} \mathrm{C}$. Endogenous peroxidase was quenched in all sections with Dual Endogenous Enzyme Block for $10 \mathrm{~min}$. Sections were incubated with mouse monoclonal antibodies against LC3B (1:50, clone 5F10, NanoTools, Teningen, Germany) for 90 min then incubated with HRP conjugated secondary antibody for $30 \mathrm{~min}$. Antibody binding was visualised by incubating with Liquid DAB+ Substrate Chromogen System for 5 min. Sections were counterstained with Harris haematoxylin and Scott's bluing reagent, dehydrated with alcohol and xylene, and mounted on glass coverslips. IHC staining on tumor section without the primary antibody was performed as the negative control.

\section{Evaluation of immunohistochemistry}

The intensity and percentage of the LC3B expression in each tissue sample were evaluated semi-quantitatively by four independent pathologists, including a senior pathologist (CSL). The scorers underwent a period of training with a multiheaded microscope to ensure consistent and reliable interpretation. Using a test series of at least 36 tissue core sections, intra- and inter-observer agreement was estimated using Kappa ( $\kappa)$ and Spearman rho ( $\rho)$. Training was ended when the desired level of agreement, consistent over time, was achieved ( $\kappa>0.6$ and $\rho>0.8)$. An average score was obtained from the duplicate cores of each tissue sample. All researchers were blinded to clinical and other laboratory data. LC3B expression was presented as cytoplasmic punctate staining. The intensity of LC3B expression was graded as follow: 0 ( $\leq 10$ punctate staining per cell), 1 (11-20 punctate staining per cell), 2 ( $>20$ punctate staining per cell without clustering) and 3 (> 20 punctate staining per cell with clustering) while the percentage of LC3B positive tumor cells was recorded from 0 to $>75 \%$. The results of staining were calculated using a quick $(\mathrm{Q})$ score, which was achieved by multiplying the percentage of positive cells $(\mathrm{P})$ by the intensity (I) hence the final score ranged from 0 to 225 [41]. LC3B expression in oropharyngeal and oral cavity SCCs were stratified using Budczies et al's Cutoff Finder application, which employed ROC curve analysis with the Manhattan distance minimization approach to threshold optimization predicting death from the LC3B value [42].

\section{Statistical analyses}

Clinicopathological characteristics of oropharyngeal and oral cavity SCCs, as well as associations between LC3B expression cohorts and clinicopathological characteristics in both SCC types, were assessed using a two-sample t-test for the continuous variables and chi-squared or Fisher's exact tests for categorical variables. The parameters were dichotomised where possible to assist the analyses.

Survival analyses were conducted for the outcomes of both overall and disease-free survival, with time to each 
outcome calculated from the date of diagnosis. Disease-free survival describes the period of time patients spend free of remission of disease and is the cumulative figure derived from all patients. Overall survival is calculated the same way but with an outcome measure of mortality rather than remission. All survival analyses were performed using IBM SPSS Statistic software version 22 (IBM, New York, USA). An event was defined as recurrence in any form or death from any cause, with only the first event taken into account. Patients without events were censored at the date of last known follow-up. Data were right-censored only. Unadjusted survival curves were obtained using Kaplan Meier estimates and compared with Log-Rank test. Cox proportional-hazards models were used to estimate the hazard ratio of clinicopathological characteristics and LC3B expression about both overall and disease-free survival in oropharyngeal and oral cavity SCCs separately. Interaction terms between HPV status and LC3B expression in oropharyngeal SCC patients were used to assess whether HPV modified the effect of LC3B expression on survival when examined in joint-effects and stratified analyses. Results for all analyses were only considered to be statistically significant if the associated $p$-value was less than 0.05 .

\section{Results}

\section{LC3B immunohistochemical staining pattern on tumor} cells

LC3B expression appeared as cytoplasmic punctate staining in both oropharyngeal and oral cavity SCC cells
(Fig. 1). No distinctive expressional difference was observed between oropharyngeal and oral cavity SCC cells. The intensity of the punctate staining pattern appeared to be heterogeneous in tumor cells (Fig. 1). Limited LC3B punctate staining was also observed in normal epithelial cells.

\section{Differential expression of LC3B about demographic and clinical characteristics between oropharyngeal and oral cavity SCC patients}

LC3B expression was stratified into low and high based on ROC curves with Manhattan distance minimization to perform the survival-data-based cut-off determination [42]. LC3B Q scores above 140.6 were stratified as high and predictive of death by the algorithm in both oropharyngeal and oral cavity SCC. Differences in LC3B expression about demographic and clinical characteristics between oropharyngeal and oral cavity SCC patients were compared and summarized in Table 1. Oropharyngeal SCC patients comprised approximately one-third of the study population (34\%) while the median age at diagnosis was identical in both SCC types (60 years). High LC3B expression was observed in 45\% of oropharyngeal SCC whereas only $29 \%$ of oral cavity SCC had a high LC3B expression $(p=<0.0001)$. There was no significant difference in demographic or clinical characteristics in oropharyngeal SCC patients with different LC3B expression. On the contrary, oral cavity SCC patients with high LC3B expression were more likely to develop the recurrent disease compared to patients with low LC3B expression (54 and 28\% respectively, $p=0.02$ ).

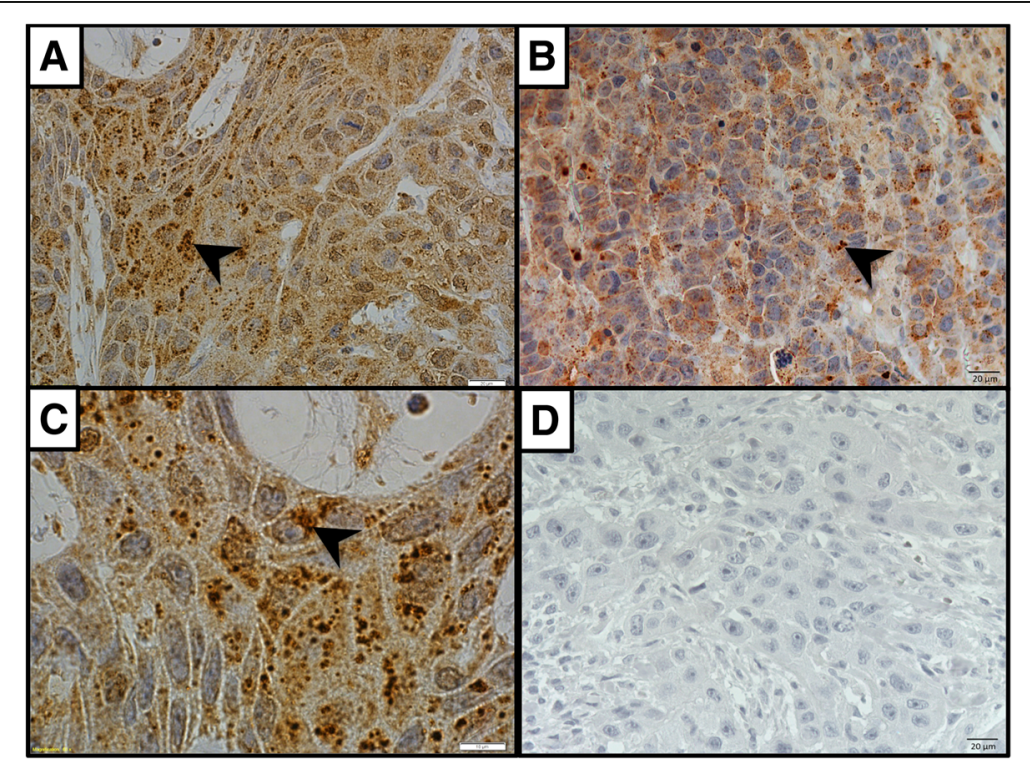

Fig. 1 LC3B immunohistochemical staining pattern. A\&B. LC3B (clone 5F10) expression appeared as cytoplasmic punctate (black arrowheads) in both oropharyngeal (a) and oral cavity (b) SCC cells. c Cytoplasmic punctate LC3B staining under higher magnification $(\times 100)$. $\mathbf{d}$ Negative control (performed immunohistochemical staining without LC3B antibody incubation). Magnification of A, B and D: $\times 40, C: \times 100$ 
Table 1 LC3B expressions and clinicopathologic variables in oropharyngeal and oral cavity SCC patients

\begin{tabular}{|c|c|c|c|c|c|c|c|c|}
\hline & \multicolumn{4}{|c|}{ Oropharyngeal SCC } & \multicolumn{4}{|c|}{ Oral Cavity SCC } \\
\hline & Total & Low LC3B & High LC3B & $P$ value & Total & Low LC3B & High LC3B & $P$ value \\
\hline Total & 47 & $26(55 \%)$ & $21(45 \%)$ & $<0.0001$ & 95 & 67 (71\%) & $28(29 \%)$ & $<0.0001$ \\
\hline Age & $41-83(60)$ & $43-83$ (59) & $41-80(62)$ & 0.46 & 28-97 (60) & 28-97 (62) & $34-83(58)$ & 0.21 \\
\hline$\leq 60$ years & 27 & $18(69 \%)$ & $9(43 \%)$ & 0.07 & 50 & 33 (49\%) & $17(61 \%)$ & 0.31 \\
\hline$>60$ years & 20 & $8(31 \%)$ & $12(57 \%)$ & & 45 & $34(51 \%)$ & $11(39 \%)$ & \\
\hline \multicolumn{9}{|l|}{ Gender } \\
\hline Male & 36 & $19(73 \%)$ & $17(81 \%)$ & 0.53 & 60 & $41(61 \%)$ & $19(68 \%)$ & 0.54 \\
\hline Female & 11 & $7(27 \%)$ & $4(19 \%)$ & & 35 & 26 (39\%) & $9(32 \%)$ & \\
\hline \multicolumn{9}{|l|}{ Tumour stage } \\
\hline $1 \& 2$ & 26 & $18(69 \%)$ & $8(38 \%)$ & 0.6 & 67 & $46(69 \%)$ & $21(75 \%)$ & 0.54 \\
\hline $3 \& 4$ & 21 & $8(31 \%)$ & $13(62 \%)$ & & 28 & 21 (31\%) & $7(25 \%)$ & \\
\hline \multicolumn{9}{|l|}{ Nodal stage } \\
\hline $0 \& 1$ & 22 & $11(42 \%)$ & $11(52 \%)$ & 0.49 & 71 & $53(79 \%)$ & $18(64 \%)$ & 0.13 \\
\hline $2 \& 3$ & 25 & $15(58 \%)$ & $10(48 \%)$ & & 24 & $14(21 \%)$ & $10(36 \%)$ & \\
\hline \multicolumn{9}{|l|}{ TNM stage } \\
\hline$|\&| \mid$ & 10 & $6(23 \%)$ & $4(19 \%)$ & 0.74 & 47 & $34(51 \%)$ & $13(46 \%)$ & 0.7 \\
\hline III \& IV & 37 & $20(77 \%)$ & 17 (81\%) & & 48 & 33 (49\%) & 15 (54\%) & \\
\hline Tumour grade & missing $=3$ & & & & missing $=2$ & & & \\
\hline $1 \& 2$ & 28 & $15(60 \%)$ & $13(68 \%)$ & 0.57 & 75 & 55 (85\%) & $20(71 \%)$ & 0.14 \\
\hline 3 & 16 & $10(40 \%)$ & $6(32 \%)$ & & 18 & $10(15 \%)$ & $8(29 \%)$ & \\
\hline \multicolumn{9}{|l|}{ Recurrence } \\
\hline Absent & 30 & $18(69 \%)$ & $12(57 \%)$ & 0.39 & 61 & $48(72 \%)$ & $13(46 \%)$ & $0.02^{*}$ \\
\hline Present & 17 & $8(31 \%)$ & $9(43 \%)$ & & 34 & $19(28 \%)$ & 15 (54\%) & \\
\hline Smoking status & missing $=2$ & & & & missing $=9$ & & & \\
\hline Never-smoker & 3 & $2(67 \%)$ & $1(33 \%)$ & $1.00^{\mathrm{a}}$ & 20 & $15(75 \%)$ & $5(25 \%)$ & $0.78^{\mathrm{a}}$ \\
\hline Ex \& current smoker & 42 & $23(55 \%)$ & $19(45 \%)$ & & 66 & 46 (70\%) & $20(30 \%)$ & \\
\hline
\end{tabular}

${ }^{a}=$ Fisher's exact test is performed due to one of the cell frequency is less than or equals to 5

$*=$ statistical significance $(p<0.05)$

\section{Kaplan Meier survival analysis}

Differences in LC3B expression about overall and disease-free survival in oropharyngeal and oral cavity SCCs were determined by Kaplan Meier survival and univariate Cox regression analyses (Fig. 2).

Oropharyngeal SCC patients with high levels of LC3B expression displayed significantly worse overall survival than patients with low levels of LC3B expression (Fig. 2a). At five years, the overall survival of patients with high levels of LC3B expression was approximately 30\% while patients with low levels of LC3B expression remained around $70 \%(p=0.007)$. Furthermore, patients with high levels of LC3B expression also displayed a high hazard ratio under univariate Cox regression analysis $(\mathrm{HR}=3.18$, 95\% CI $1.31-7.71, p=0.01)$. There was a trend towards worse disease-free survival in patients with high LC3B expression (Fig. 2b). However this failed to reach statistical significance $(p=0.076)$.
In oral cavity SCC patients, Kaplan Meier survival analysis showed that patients with high levels of LC3B expression had significantly worse overall and disease-free survival than patients with low levels of LC3B expression (Fig. 2c \& d). The overall survival of patients (Fig. 2c) with high levels of LC3B expression decreased to approximately 30\% while patients with low levels of LC3B was double $(60 \%)$ at five years $(p=0.046)$. Regarding disease-free survival (Fig. 2d), patients with high levels of LC3B expression decreased to approximately $45 \%$ while patients with low levels of LC3B expression remained at $70 \%$ at five years $(p=0.011)$. Univariate Cox regression analysis revealed that oral cavity SCC patients with high levels of LC3B expression displayed a higher hazard ratio in disease-free survival $(\mathrm{HR}=2.36,95 \%$ CI 1.19-4.67, $p=0.014)$, although a relatively high ratio was also observed in the overall survival, it is just short of statistical significance $(\mathrm{HR}=1.83,95 \% \mathrm{CI} 1-3.37, p=0.051)$. 

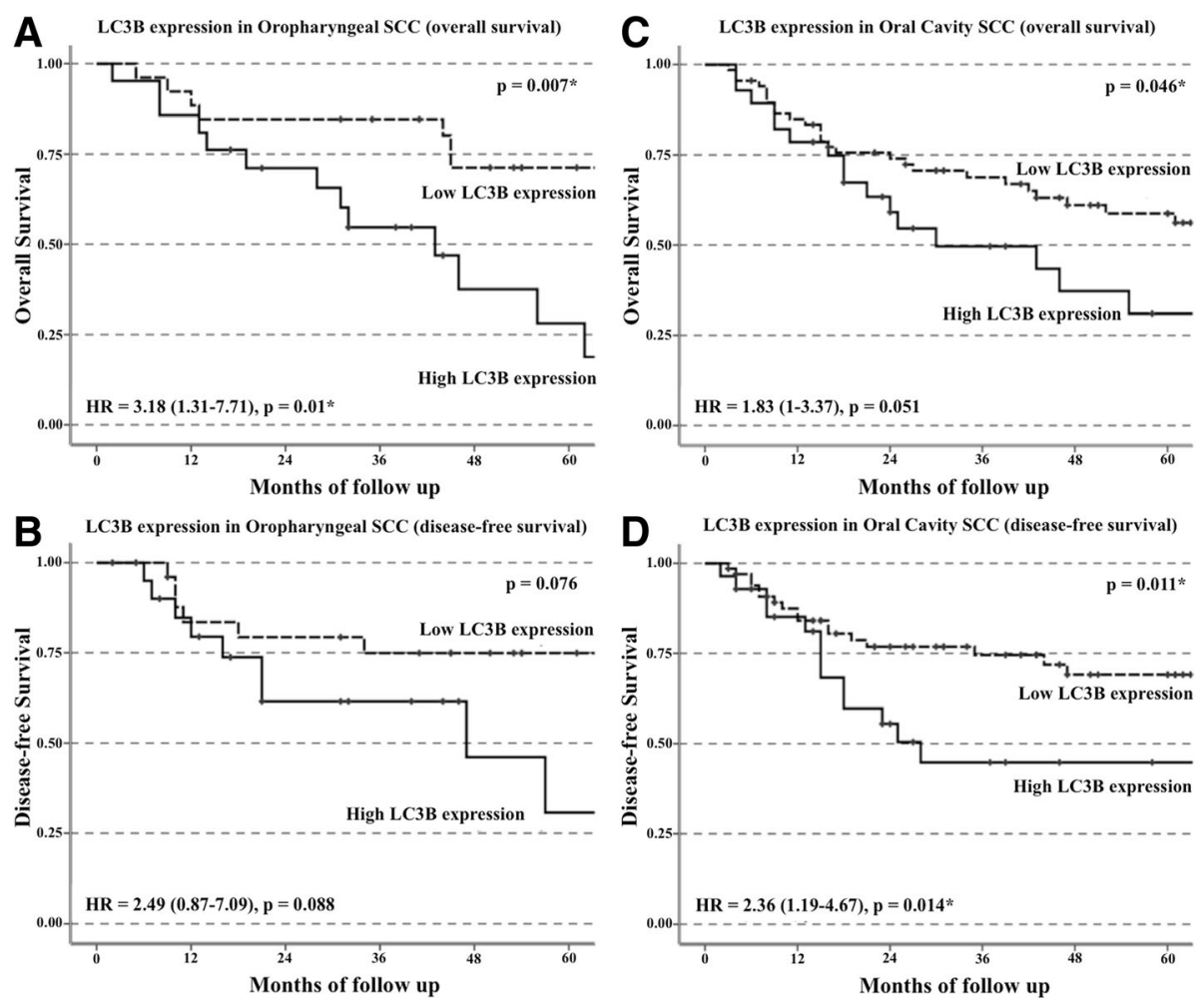

Fig. 2 Kaplan Meier survival curves of LC3B expression in oropharyngeal $(n=47)$ and oral cavity $(n=95)$ SCC patients. Although oropharyngeal SCC patients with high LC3B expression displayed worse survival than patients with low LC3B expression in both overall survival (a) and disease-free survival (b), only overall survival reached statistical significance ( $p=0.007$, Log Rank test). Oral cavity SCC patients with high LC3B expression displayed worse survival than patients with low LC3B expression in both overall survival (c) and disease-free survival $(\mathbf{d})(p=0.046$ and 0.011 respectively, Log Rank test)

\section{Cox proportional hazard ratio analysis}

The prognostic significance of LC3B expression in oropharyngeal and oral cavity SCC patients was further analysed using univariate and multivariate Cox proportional hazard ratio models, as summarized in Tables 2 and 3 respectively.

Clinicopathological features that are associated with better overall survival of patients with oropharyngeal SCC include male gender, and ironically with advanced tumor grade (Table 2) under multi-variable analysis $(H R=0.23$, 95\% CI 0.07-0.76, $p=0.016$ and $\mathrm{HR}=0.23$, 95\% CI $0.07-$ $0.78, p=0.018$ respectively), but the latter is most likely related to HPV status. As previously mentioned, HPV positive oropharyngeal SCC patients tend to display better survival outcome than HPV-negative patients while such population is rapidly increased in male patients [12]. Furthermore, HPV positive SCC cells often displayed basaloid differentiation that is considered as advanced grade [43]. On the other hand, advanced $\mathrm{N}$ stages were associated with higher risk under multi-variable analysis $(\mathrm{HR}=5.21$, 95\% CI 1.43-19.01, $p=0.012$ ). In the case of LC3B expression, patients with high LC3B expression were exposed to higher risk under both univariate and multivariate analysis
$(\mathrm{HR}=3.18,95 \% \mathrm{CI} 1.31-7.71, p=0.01$ and $\mathrm{HR}=4.02$, $95 \%$ CI 1.38-11.74, $p=0.011$ respectively), the significance of the biomarker is retained when the influence of other parameters is accounted by the multivariate analysis suggesting it is an independent prognostic marker.

Considering overall survival of oral cavity SCC patients (Table 3A), age greater than 60 years was associated with higher risk under both univariate and multivariate analysis $(\mathrm{HR}=2.25,95 \%$ CI $1.24-4.11, p=0.008$ and $\mathrm{HR}=3.01$, 95\% CI 1.38-6.56, $p=0.006$ respectively). Although univariate analysis of patients with advanced tumor grade was also shown to be at higher risk $(\mathrm{HR}=2.32,95 \% \mathrm{CI}$ 1.24-4.32, $p=0.008$ ), the influence of this variable was reduced when other covariates were introduced into the model using multivariate analysis $(\mathrm{HR}=2.29,95 \% \mathrm{CI} 1-$ 5.26, $p=0.051$ ). In the disease-free survival of oral cavity patients (Table 3B), patients with advanced $\mathrm{N}$ stages were associated with higher risk under both univariate and multivariable analysis $(\mathrm{HR}=2.07,95 \% \mathrm{CI} 1.02-4.22, p=0.045$ and $\mathrm{HR}=3.42$, 95\% CI 1.21-9.67, $p=0.021$ respectively). However, high LC3B expression did not appear to be an independent prognostic factor in either overall or disease-free survival for the oral cavity SCC patients $(p=0.19$ and 0.138 
Table 2 Univariate and multivariate Cox proportional hazard analyses of clinicopathologic variables for overall and diseasefree survival in oropharyngeal SCC patients

\begin{tabular}{|c|c|c|c|c|}
\hline \multicolumn{5}{|l|}{ Oropharyngeal SCC } \\
\hline \multirow[t]{2}{*}{ Variable } & \multicolumn{2}{|c|}{ Univariate analysis } & \multicolumn{2}{|c|}{ Multivariate analysis } \\
\hline & $\begin{array}{l}\text { Hazard ratio } \\
(95 \% \text { Cl) }\end{array}$ & $P$ value & $\begin{array}{l}\text { Hazard ratio } \\
(95 \% \text { Cl) }\end{array}$ & $P$ value \\
\hline \multicolumn{5}{|l|}{ 2A. Overall survival } \\
\hline $\begin{array}{l}\text { Age } \\
(>60 \mathrm{yr} . \mathrm{vs} \leq 60 \mathrm{yr})\end{array}$ & $\begin{array}{l}2.13 \\
(0.96-4.72)\end{array}$ & 0.062 & $\begin{array}{l}2.55 \\
(0.86-7.58)\end{array}$ & 0.093 \\
\hline $\begin{array}{l}\text { Gender } \\
\text { (male vs female) }\end{array}$ & $\begin{array}{l}0.64 \\
(0.25-1.69)\end{array}$ & 0.372 & $\begin{array}{l}0.23 \\
(0.07-0.76)\end{array}$ & $0.016^{*}$ \\
\hline $\begin{array}{l}\text { Smoking status }{ }^{a} \\
\text { (ex \& current vs never) }\end{array}$ & $\begin{array}{l}1.49 \\
(0.2-11.23)\end{array}$ & 0.697 & $\begin{array}{l}0.64 \\
(0.07-5.68)\end{array}$ & 0.691 \\
\hline $\begin{array}{l}\text { Tumour grade b } \\
\text { (3 vs 1\&2) }\end{array}$ & $\begin{array}{l}0.69 \\
(0.27-1.81)\end{array}$ & 0.456 & $\begin{array}{l}0.23 \\
(0.07-0.78)\end{array}$ & $0.018^{*}$ \\
\hline $\begin{array}{l}\text { Tstage } \\
\text { (3\&4 vs 1\&2) }\end{array}$ & $\begin{array}{l}1.51 \\
(0.69-3.31)\end{array}$ & 0.307 & $\begin{array}{l}0.27 \\
(0.07-1.03)\end{array}$ & 0.055 \\
\hline $\begin{array}{l}\text { N stage } \\
\text { (2\&3 vs } 0 \& 1)\end{array}$ & $\begin{array}{l}1.39 \\
(0.64-3.05)\end{array}$ & 0.407 & $\begin{array}{l}5.21 \\
(1.43-19.01)\end{array}$ & $0.012^{*}$ \\
\hline $\begin{array}{l}\text { LC3B expression } \\
\text { (high vs low) }\end{array}$ & $\begin{array}{l}3.18 \\
(1.31-7.71)\end{array}$ & $0.01^{*}$ & $\begin{array}{l}4.02 \\
(1.38-11.74)\end{array}$ & $0.011^{*}$ \\
\hline \multicolumn{5}{|l|}{ 2B. Disease-free survival } \\
\hline $\begin{array}{l}\text { Age } \\
(>60 \mathrm{yr} . \mathrm{vs} \leq 60 \mathrm{yr})\end{array}$ & $\begin{array}{l}3.9 \\
(1.35-11.26)\end{array}$ & $0.012^{*}$ & $\begin{array}{l}3.24 \\
(0.89-11.81)\end{array}$ & 0.075 \\
\hline $\begin{array}{l}\text { Gender } \\
\text { (male vs female) }\end{array}$ & $\begin{array}{l}0.75 \\
(0.24-2.39)\end{array}$ & 0.631 & $\begin{array}{l}0.5 \\
(0.11-2.35)\end{array}$ & 0.379 \\
\hline $\begin{array}{l}\text { Smoking status }{ }^{a} \\
\text { (ex \& current vs never) }\end{array}$ & NC & NC & NC & NC \\
\hline $\begin{array}{l}\text { Tumour grade b } \\
\text { (3 vs } 1 \& 2 \text { ) }\end{array}$ & $\begin{array}{l}0.61 \\
(0.19-1.98)\end{array}$ & 0.409 & $\begin{array}{l}0.39 \\
(0.09-1.78)\end{array}$ & 0.226 \\
\hline $\begin{array}{l}\text { Tstage } \\
\text { (3\&4 vs } 1 \& 2)\end{array}$ & $\begin{array}{l}1.46 \\
(0.55-3.91)\end{array}$ & 0.447 & $\begin{array}{l}0.53 \\
(0.13-2.14)\end{array}$ & 0.372 \\
\hline $\begin{array}{l}\text { N stage } \\
\text { (2\&3 vs } 0 \& 1)\end{array}$ & $\begin{array}{l}1.21 \\
(0.45-3.26)\end{array}$ & 0.705 & $\begin{array}{l}2.33 \\
(0.57-9.49)\end{array}$ & 0.237 \\
\hline $\begin{array}{l}\text { LC3B expression } \\
\text { (high vs low) }\end{array}$ & $\begin{array}{l}2.49 \\
(0.87-7.09)\end{array}$ & 0.088 & $\begin{array}{l}1.91 \\
(0.57-6.36)\end{array}$ & 0.293 \\
\hline
\end{tabular}

$\mathrm{a}=$ missing 2 cases

${ }^{b}=$ missing 4 cases

* = statistical significance $(p<0.05)$

$\mathrm{NC}=$ not calculated (coefficient cannot be estimated due to imbalance data)

respectively). Smoking status appeared to introduce a systematic bias into the multivariable analysis precluding the construction of a stable model as reported in our previous study [14].

\section{Effect of combining HPV and LC3B in oropharyngeal SCC patients}

$\mathrm{HPV}$ is known to be an important prognostic factor in oropharyngeal SCC patients as HPV-positive patients tend to display better prognosis $[12,13]$, similarly, our previous study with the same cohort had also observed that HPV positivity is associated with better survival outcome in oropharyngeal SCC but not in oral cavity SCC patients [14]. To further investigate whether HPV modified the effect of LC3B expression on the survival of oropharyngeal SCC patients, the prognostic significance of a combination of HPV and LC3B expression was evaluated in joint-effects and stratified analyses, as summarized in Table 4. After adjustment for age, gender, tumor grade, $\mathrm{T}$ - and $\mathrm{N}$-stage, the best outcomes were seen in patients with HPV-positive/low LC3B expression cancers and the worst in those with HPV-negative/high LC3B expression cancers. Relative to patients with HPV-positive/low LC3B expression cancers, those with HPV-negative/high LC3B expression cancers displayed poor overall survival in the joint-effects analyses $(\mathrm{HR}=4.76,95 \%$ CI 1.23-18.48, $p=0.024)$. This effect was particularly pronounced in the HPV negative patients as revealed by the stratified presentation $(\mathrm{HR}=18.71,95 \% \mathrm{CI}$ 1.3-270.24, $p=0.032$ ). Although a similar trend was also observed in the disease-free survival, it was not statistically significant $(p>0.05)$.

\section{Discussion}

In the current study, the LC3B expression on immunohistochemistry is characterized by a punctate cytoplasmic pattern in both oropharyneal and oral cavity SCC cells. To date, LC3B expression patterns in cancer are reported predominantly cytoplasmic [38, 39, 44-50], meanwhile other patterns such as large globule (stone) like structure and crescentic (perinuclear) patterns are also observed in oesophageal adenocarcinoma and triple negative breast cancer (TNBC) $[39,48]$. In the case of oral SCC, the LC3B expression is characterized by punctate cytoplasmic pattern [32], which is consistent with the current study.

High LC3B expression correlates with poor prognosis in both oropharyngeal and oral cavity SCC with stronger prognostic significance found in oropharyngeal SCC patients. Oropharyngeal SCC patients with HPV-negative/ high LC3B expression were found to have poorer overall survival. LC3B is reported to be an effective prognostic marker in various cancers. The high LC3B expression is an independent prognostic marker for poor overall and disease-free survival in locally advanced breast cancer and TNBC [38, 39]. In astrocytoma, high LC3B expression alone, as well as high co-expression with CD133, a cancer stem cell-like marker, is associated with poor overall survival [46]. In the case of hepatocellular carcinoma, the high LC3B expression is associated with advanced TNM stages, vascular invasion, lymph node metastasis as well as an independent prognostic marker for poor overall survival [47]. In prostate adenocarcinoma, the high LC3B expression is an independent prognostic marker for a high Gleason score [45]. Despite that multiple LC3B expression patterns are observed in oesophageal adenocarcinoma, only large globule like structure pattern emerged as an independent prognostic marker for poor overall survival irrespective of treatment [48]. In the case of oral SCC, although Kaplan Meier and univariate analyses show that 
Table 3 Univariate and multivariate Cox proportional hazard analyses of clinicopathologic variables for overall and disease-free survival in oral cavity SCC patients

\begin{tabular}{|c|c|c|c|c|}
\hline \multicolumn{5}{|l|}{ Oral cavity SCC } \\
\hline \multirow[t]{2}{*}{ Variable } & \multicolumn{2}{|l|}{ Univariate analysis } & \multicolumn{2}{|l|}{ Multivariate analysis } \\
\hline & Hazard ratio (95\% Cl) & $P$ value & Hazard ratio (95\% Cl) & $P$ value \\
\hline \multicolumn{5}{|l|}{ 3A. Overall survival } \\
\hline $\begin{array}{l}\text { Age } \\
(>60 \mathrm{yr} . \mathrm{vs} \leq 60 \mathrm{yr})\end{array}$ & $2.25(1.24-4.11)$ & $0.008^{*}$ & $3.01(1.38-6.56)$ & $0.006^{*}$ \\
\hline $\begin{array}{l}\text { Gender } \\
\text { (male vs female) }\end{array}$ & $1.02(0.55-1.88)$ & 0.949 & $0.89(0.43-1.84)$ & 0.748 \\
\hline $\begin{array}{l}\text { Smoking status }{ }^{a} \\
\text { (ex \& current vs never) }\end{array}$ & $0.56(0.28-1.13)$ & 0.104 & $0.37(0.17-0.82)$ & $0.014^{*}$ \\
\hline $\begin{array}{l}\text { Tumour grade }{ }^{b} \\
\text { (3 vs 1\&2) }\end{array}$ & $2.32(1.24-4.32)$ & $0.008^{*}$ & $2.29(1-5.26)$ & 0.051 \\
\hline $\begin{array}{l}\text { Tstage } \\
\text { (3\&4 vs 1\&2) }\end{array}$ & $1.68(0.92-3.09)$ & 0.093 & $1.49(0.7-3.16)$ & 0.301 \\
\hline $\begin{array}{l}\text { N stage } \\
\text { (2\&3 vs } 0 \& 1)\end{array}$ & $1.46(0.78-2.73)$ & 0.243 & $1.97(0.77-5.05)$ & 0.158 \\
\hline $\begin{array}{l}\text { LC3B expression } \\
\text { (high vs low) }\end{array}$ & $1.83(1-3.37)$ & 0.051 & $1.67(0.78-3.58)$ & 0.19 \\
\hline \multicolumn{5}{|l|}{ 3B. Disease-free survival } \\
\hline $\begin{array}{l}\text { Age } \\
(>60 \mathrm{yr} . \text { vs } \leq 60 \mathrm{yr})\end{array}$ & $1.69(0.86-3.35)$ & 0.13 & $1.49(0.63-3.49)$ & 0.361 \\
\hline $\begin{array}{l}\text { Gender } \\
\text { (male vs female) }\end{array}$ & $0.9(0.45-1.8)$ & 0.767 & $0.77(0.33-1.82)$ & 0.553 \\
\hline $\begin{array}{l}\text { Smoking status }{ }^{a} \\
\text { (ex \& current vs never) }\end{array}$ & $0.93(0.38-2.27)$ & 0.867 & $0.68(0.26-1.82)$ & 0.446 \\
\hline $\begin{array}{l}\text { Tumour grade } \\
\text { ( } 3 \text { vs } 1 \& 2 \text { ) }\end{array}$ & $1.82(0.87-3.83)$ & 0.114 & $2.16(0.79-5.91)$ & 0.132 \\
\hline $\begin{array}{l}\text { Tstage } \\
\text { (3\&4 vs 1\&2) }\end{array}$ & $1.09(0.51-2.36)$ & 0.82 & $0.81(0.33-2)$ & 0.643 \\
\hline $\begin{array}{l}\text { N stage } \\
\text { ( } 2 \& 3 \text { vs } 0 \& 1)\end{array}$ & $2.07(1.02-4.22)$ & $0.045^{*}$ & $3.42(1.21-9.67)$ & $0.021^{*}$ \\
\hline $\begin{array}{l}\text { LC3B expression } \\
\text { (high vs low) }\end{array}$ & $2.36(1.19-4.67)$ & $0.014^{*}$ & $1.82(0.83-4)$ & 0.138 \\
\hline
\end{tabular}

$\mathbf{a}=$ missing 9 cases

$\mathbf{b}=$ missing 2 cases

* $=$ statistical significance $(p<0.05)$

high LC3B expression correlated with poor disease-free survival, it did not appear to be an independent prognostic factor in multivariate analysis [32]. The current study further investigated for any prognostic difference in LC3B expression between oral cavity and oropharyngeal SCC. Similar to Liu et al., high LC3B expression is associated with poor overall and disease-free survival in oral cavity SCC, but it also did not emerge as an independent prognostic marker. In contrast to oral cavity SCC, the high LC3B expression is strongly associated with poor overall survival outcome in oropharyngeal SCC patients thus raising the possibility of its use as an independent prognostic marker. Our previous study showed that HPV is associated with better survival outcome in oropharyngeal SCC but not in oral cavity SCC patients [14], furthermore, the current study also showed that patients with HPV-negative/high
LC3B expression displayed the most unfavourable survival outcome. Since LC3B displays different prognostic value amongst different cancers, it is likely that our finding further supports the biological differences between oropharyngeal and oral cavity SCC.

The cohort was not analysed based on different treatment regimes because of the small number of cases, which resulted in numbers that are too small in the stratified groups to have any meaningful statistical power. However, in future an expanded cohort will be required to generate data that has the sufficient statistical power be analysed in the context of the recently updated OPSCC nomogram [51].

Although the current study demonstrated that high autophagy correlates with poor prognosis in oropharyngeal and oral cavity SCC, autophagy can be involved in either 
Table 4 Association between HPV and LC3B status on overall and disease-free survival in oropharyngeal SCC $(n=47)$

\begin{tabular}{|c|c|c|c|c|}
\hline \multirow[t]{2}{*}{ LC3B and HPV status } & \multicolumn{2}{|l|}{ Overall survival } & \multicolumn{2}{|c|}{ Disease-free survival } \\
\hline & $H R^{*}(95 \% \mathrm{Cl})$ & $P$ value & $H R^{*}(95 \% \mathrm{Cl})$ & $P$ value \\
\hline \multicolumn{5}{|l|}{ A. Joint-effects presentation } \\
\hline HPV positive/Low LC3B $(n=18)$ & 1.00 & & 1.00 & \\
\hline HPV positive/High LC3B $(n=11)$ & $2.85(0.77-10.47)$ & 0.115 & $1.91(0.36-10.22)$ & 0.449 \\
\hline HPV negative/Low LC3B $(n=8)$ & $0.82(0.24-2.82)$ & 0.756 & $1.45(0.30-7.15)$ & 0.647 \\
\hline HPV negative/High LC3B $(n=10)$ & $4.76(1.23-18.48)$ & $0.024^{*}$ & $2.83(0.57-0.57)$ & 0.205 \\
\hline \multicolumn{5}{|l|}{ B. Stratified presentation } \\
\hline HPV positive/Low LC3B $(n=18)$ & 1.00 & & 1.00 & \\
\hline HPV positive/High LC3B $(n=11)$ & $2.95(0.66-13.25)$ & 0.159 & $1.83(0.28-11.79)$ & 0.524 \\
\hline HPV negative/Low LC3B $(n=8)$ & 1.00 & & 1.00 & \\
\hline HPV negative/High LC3B $(n=10)$ & $18.71(1.3-270.24)$ & $0.032^{*}$ & $3.35(0.31-36.78)$ & 0.323 \\
\hline
\end{tabular}

Clinical variables adjusted

${ }^{*}=$ statistical significance $(p<0.05)$

the promotion or inhibition of cancer cell survival. Atg6/ Beclin-1 is thought to suppress tumorigenesis, meanwhile, damage-regulated autophagy modulator (DRAM) is essential for p53 mediated apoptosis and p53 also induces autophagy in a DRAM-dependent manner [24].

It is essential to further clarify the role of autophagy in oropharyngeal and oral cavity SCC progression as such information would become useful when autophagy is considered within therapeutic strategies for these tumors. Inhibition of autophagy through pharmacological inhibitors and RNA interference (RNAi) of autophagy-related genes is shown to enhance chemosensitivity and photosensitivity in cancer cell models [24]. Specifically, an in-vitro study showed that depletion of LC3 gene using RNAi enhances the sensitivity of hepatocellular carcinoma cells to Epirubicin [52]. 3-Methyladenine (3-MA), which inhibits autophagy by preventing autophagosome formation via the inhibition of class III phosphatidylinositol 3-kinase (PI3K), is shown to enhance the cytotoxicity of numerous chemotherapy agents including Cisplatin, 5-fluorouracil (5-FU), Tamoxifen, Trastuzumab and Camptothecin [53-58]. Similar to 3-MA, Chloroquine (CQ), a 4-aminoquinoline drug that is widely used to treat malaria, prevents autolysosome fusion, and it is also reported to enhance the efficacy of Cisplatin, 5-FU, Gefitinib and Paclitaxel [59-65]. Radiotherapy (RT) is reported to induce autophagy activity in cancer cells and speculated to play a major role in RT resistance. Autophagy inhibition through CQ and/or RNAi increases the radiosensitivity and chemo-radiosensitivity in cancer cell lines including breast carcinoma, colorectal cancer, non-small cell lung cancer and glioma stem cells [66-69]. Although the therapeutic significance of autophagy inhibition in response to RT is yet to be functionally tested on oropharyngeal and oral cavity SCC cells, autophagy activity is reported to be elevated in irradiated oral cavity SCC cells
[70]. Recently, the trial of a nanomedicine employing a polymeric co-delivery system, allowing the sequential release of the autophagy inhibitor, LY294002, and a chemotherapeutic agent, doxorubicin, shows promising results in oral cavity (tongue) SCC cells [30]. As the current study observed that autophagy is associated with both oropharyngeal and oral cavity SCC progression, future studies should compare the effects of autophagy inhibition between oropharyngeal and oral cavity SCC cell lines in response to radio and chemotherapy. Additionally, combined investigation between LC3B expressions and other independent prognostic markers including EGFR status, matted nodes, p27 and cyclin D1 in oropharyngeal SCC patients might help to further stratify other patient subgroups for different therapeutic approaches [71-73].

\section{Conclusions}

In conclusion, we propose that LC3B is an independent prognostic marker for oropharyngeal SCC patients due to the strong association between high LC3B expression and poor overall survival outcome in our patient cohort; however, this was not observed in oral cavity SCC patients. Furthermore, the current study further supports a biological difference between oropharyngeal and oral cavity SCC as LC3B expression displayed a different prognostic significance in these malignancies. As autophagy appears to be involved in oropharyngeal and oral cavity SCC progression, future studies should evaluate the effects of autophagy inhibition of these tumors in response to chemo radiotherapy and chemotherapy. The possibility that oropharyngeal SCC patients with negative HPV status and high LC3B expression were at particular risk of a poor outcome warrants further investigation in prospective studies with larger numbers. If our findings are confirmed, pretreatment 
testing for LC3B expression in addition to HPV will help to better stratify oropharyngeal SCC patients in the setting of tailored treatment. In particular, the group of patients with HPV-negative/high LC3B expression cancers would benefit from intensified treatment.

\author{
Abbreviations \\ 3-MA: 3-Methyladenine; 5-FU: 5-fluorouracil; CQ: Chloroquine; FFPE: Formalin \\ fixed paraffin embedded; HPV: Human papillomavirus; I: Intensity; \\ IHC: Immunohistochemistry; LC3: Microtubule-associated protein light chain \\ 3; P: Positive cells; PI3K: Class III phosphatidylinositol 3-kinase; Q: Quick score; \\ RNAi: RNA interference; ROI: Regions of interest; RT: Radiotherapy; \\ SCC: Squamous cell carcinoma; TMAs: Tissue microarrays; TNBC: Triple \\ negative breast cancer
}

\section{Acknowledgments}

We would like to thank staffs in Department of Anatomical Pathology, Sydney South West Pathology Service (SSWPS), Liverpool Hospital for the assistance of specimen retrieval.

\section{Funding}

This design of the study and collection, analysis, interpretation of data and in writing the manuscript was supported by internal funds and the Centre for Oncology Education and Research Translation (CONCERT) is funded by the Cancer Institute of New South Wales, Australia.

\section{Availability of data and materials}

The dataset supporting the conclusions of this article is included within the article and its additional files.

\section{Authors' contributions}

$\mathrm{KL}$ contributed to drafting of the manuscript. KL and CSL contributed to conception and design. KL, SM and JSW contributed to development of methodology. KL, CSL, MCK, JLY, JW, AS and DF contributed to acquisition of data. KL, SM and CSL contributed to analysis and interpretation of data. All authors read and approved the final manuscript.

\section{Ethics approval and consent to participate}

The study was approved by South West Sydney Local Health District Human Research Ethics Committee (HREC/13/LPOOL/449). All experimental procedures were conducted in accordance with the Declaration of Helsinki.

\section{Competing interests}

The authors declare that they have no competing interests.

\section{Publisher's Note}

Springer Nature remains neutral with regard to jurisdictional claims in published maps and institutional affiliations.

\section{Author details}

${ }^{1}$ Sydney Medical School, The University of Sydney, Sydney, Australia. ${ }^{2}$ Discipline of Pathology, School of Medicine, Western Sydney University, Sydney, Australia. ${ }^{3}$ Centre for Oncology Education and Research Translation (CONCERT), Ingham Institute for Applied Medical Research, Sydney, Australia. ${ }^{4}$ Department of Anatomical Pathology, Sydney South West Pathology Service (SSWPS) Liverpool Hospital, Sydney, Australia. ${ }^{5}$ Bosch Institute, The University of Sydney, Sydney, Australia. ' Melanoma Institute Australia, Sydney, Australia. ${ }^{7}$ Faculty of Medicine, University of New South Wales, Sydney, Australia. ${ }^{8}$ Department of Head \& Neck Surgery, Liverpool Hospital, Sydney, Australia. ${ }^{9}$ Department of Radiation Oncology, Liverpool Hospital, Sydney, Australia.

${ }^{10}$ Ingham Institute for Applied Medical Research, 1 Campbell St, Liverpool, NSW 2170, Australia.

Received: 20 June 2017 Accepted: 21 May 2018 Published online: 01 June 2018

\section{References}

1. Gillison ML. Current topics in the epidemiology of oral cavity and oropharyngeal cancers. Head Neck. 2007;29:779-92.
2. Ferlay J, Soerjomataram I, Dikshit R, Eser S, Mathers C, Rebelo M, et al. Cancer incidence and mortality worldwide: sources, methods and major patterns in GLOBOCAN 2012. Int J Cancer. 2015;136:E359-86.

3. Ariyawardana A, Johnson NW. Trends of lip, oral cavity and oropharyngeal cancers in Australia 1982-2008: overall good news but with rising rates in the oropharynx. BMC Cancer. 2013;13:333.

4. Chaturvedi AK, Anderson WF, Lortet-Tieulent J, Curado MP, Ferlay J, Franceschi S, et al. Worldwide trends in incidence rates for oral cavity and oropharyngeal cancers. J Clin Oncol. 2013;31:4550-9.

5. Monteiro LS, Antunes L, Bento MJ, Warnakulasuriya S. Incidence rates and trends of lip, oral and oro-pharyngeal cancers in Portugal. J Oral Pathol Med. 2013;42:345-51.

6. Shin A, Jung YS, Jung KW, Kim K, Ryu J, Won YJ. Trends of human papillomavirus-related head and neck cancers in Korea: national cancer registry data. Laryngoscope. 2013;123:E30-7.

7. Steliarova-Foucher E, O'Callaghan M, Ferlay J. European Cancer Observatory: Cancer Incidence, Mortality, Preva- lence and Survival in Europe. Version 1.0 European Network of Cancer Registries, International Agency for Research on Cancer. 2013.

8. Braakhuis BJ, Leemans CR, Visser O. Incidence and survival trends of head and neck squamous cell carcinoma in the Netherlands between 1989 and 2011. Oral Oncol. 2014;50:670-5.

9. Howlader N, Noone AM, Krapcho M, Miller D, Bishop K, Kosary CL, et al. SEER Cancer Statistics Review, 1975-2014. Bethesda: National Cancer Institute. 2016. https://seer.cancer.gov/csr/1975_2014/. Accessed April 2017.

10. Hong A, Lee CS, Jones D, Veillard AS, Zhang M, Zhang X, et al. Rising prevalence of human papillomavirus-related oropharyngeal cancer in Australia over the last 2 decades. Head Neck. 2016;38:743-50.

11. Chi AC, Day TA, Neville BW. Oral cavity and oropharyngeal squamous cell carcinoma-an update. CA Cancer J Clin. 2015;65:401-21.

12. Chaturvedi AK, Engels EA, Anderson WF, Gillison ML. Incidence trends for human papillomavirus-related and -unrelated oral squamous cell carcinomas in the United States. J Clin Oncol. 2008;26:612-9.

13. Hong AM, Dobbins TA, Lee CS, Jones D, Harnett GB, Armstrong BK, et al. Human papillomavirus predicts outcome in oropharyngeal cancer in patients treated primarily with surgery or radiation therapy. Br J Cancer. 2010;103:1510-7.

14. Lai K, Killingsworth M, Matthews S, Caixeiro N, Evangelista C, Wu X, et al. Differences in survival outcome between oropharyngeal and oral cavity squamous cell carcinoma in relation to HPV status. J Oral Pathol Med. 2017; 46:574-82.

15. Cruz IB, Snijders PJ, Steenbergen RD, Meijer CJ, Snow GB, Walboomers JM, et al. Age-dependence of human papillomavirus DNA presence in oral squamous cell carcinomas. Eur J Cancer B Oral Oncol. 1996;32B:55-62.

16. Sugiyama M, Bhawal UK, Dohmen T, Ono S, Miyauchi M, Ishikawa T. Detection of human papillomavirus-16 and HPV-18 DNA in normal, dysplastic, and malignant oral epithelium. Oral Surg Oral Med Oral Pathol Oral Radiol Endod. 2003;95:594-600.

17. Smith EM, Ritchie JM, Summersgill KF, Klussmann JP, Lee JH, Wang D, et al. Age, sexual behavior and human papillomavirus infection in oral cavity and oropharyngeal cancers. Int J Cancer. 2004;108:766-72.

18. Laco J, Vosmikova H, Novakova V, Celakovsky P, Dolezalova H, Tucek L, et al. The role of high-risk human papillomavirus infection in oral and oropharyngeal squamous cell carcinoma in non-smoking and non-drinking patients: a clinicopathological and molecular study of 46 cases. Virchows Arch. 2011:458:179-87.

19. Simonato LE, Garcia JF, Sundefeld ML, Mattar NJ, Veronese LA, Miyahara Gl. Detection of HPV in mouth floor squamous cell carcinoma and its correlation with clinicopathologic variables, risk factors and survival. J Oral Pathol Med. 2008:37:593-8.

20. Gudleviciene Z, Smailyte G, Mickonas A, Pikelis A. Prevalence of human papillomavirus and other risk factors in Lithuanian patients with head and neck cancer. Oncology. 2009;76:205-8.

21. Lohavanichbutr P, Houck J, Fan W, Yueh B, Mendez E, Futran N, et al. Genomewide gene expression profiles of HPV-positive and HPV-negative oropharyngeal cancer: potential implications for treatment choices. Arch Otolaryngol Head Neck Surg. 2009;135:180-8.

22. Elango KI, Suresh A, Erode EM, Subhadradevi L, Ravindran HK, lyer SK, et al. Role of human papilloma virus in oral tongue squamous cell carcinoma. Asian Pac J Cancer Prev. 2011;12:889-96.

23. Lee LA, Huang CG, Liao CT, Lee LY, Hsueh $C$, Chen $T C$, et al. Human papillomavirus-16 infection in advanced oral cavity cancer patients is 
related to an increased risk of distant metastases and poor survival. PLoS One. 2012;7:e40767.

24. Lai K, Killingsworth MC, Lee CS. The significance of autophagy in colorectal cancer pathogenesis and implications for therapy. J Clin Pathol. 2014;67:854-8.

25. Mari M, Tooze SA, Reggiori F. The puzzling origin of the autophagosomal membrane. F1000 Biol Rep. 2011;3:25.

26. Mathew $R$, White E. Autophagy in tumorigenesis and energy metabolism: friend by day, foe by night. Curr Opin Genet Dev. 2011;21:113-9.

27. Schneider JL, Cuervo AM. Autophagy and human disease: emerging themes. Curr Opin Genet Dev. 2014;26C:16-23.

28. White E, DiPaola RS. The double-edged sword of autophagy modulation in cancer. Clin Cancer Res. 2009;15:5308-16.

29. Amaravadi RK, Lippincott-Schwartz J, Yin XM, Weiss WA, Takebe N, Timmer W, et al. Principles and current strategies for targeting autophagy for cancer treatment. Clin Cancer Res. 2011;17:654-66.

30. Saiyin W, Wang D, Li L, Zhu L, Liu B, Sheng L, et al. Sequential release of autophagy inhibitor and chemotherapeutic drug with polymeric delivery system for oral squamous cell carcinoma therapy. Mol Pharm. 2014;11:1662-75.

31. Tang JY, Hsi E, Huang YC, Hsu NC, Chu PY, Chai CY. High LC3 expression correlates with poor survival in patients with oral squamous cell carcinoma. Hum Pathol. 2013:44:2558-62.

32. Liu JL, Chen FF, Lung J, Lo CH, Lee FH, Lu YC, et al. Prognostic significance of p62/SQSTM1 subcellular localization and LC3B in oral squamous cell carcinoma. Br J Cancer. 2014;111:944-54.

33. Tanida I, Ueno T, Kominami E. LC3 conjugation system in mammalian autophagy. Int J Biochem Cell Biol. 2004;36:2503-18.

34. Weidberg H, Shvets E, Shpilka T, Shimron F, Shinder V, Elazar Z. LC3 and GATE-16/GABARAP subfamilies are both essential yet act differently in autophagosome biogenesis. EMBO J. 2010;29:1792-802.

35. He H, Dang Y, Dai F, Guo Z, Wu J, She X, et al. Post-translational modifications of three members of the human MAP1LC3 family and detection of a novel type of modification for MAP1LC3B. J Biol Chem. 2003;278:29278-87.

36. Giatromanolaki A, Koukourakis MI, Harris AL, Polychronidis A, Gatter KC, Sivridis E. Prognostic relevance of light chain 3 (LC3A) autophagy patterns in colorectal adenocarcinomas. J Clin Pathol. 2010;63:867-72.

37. Sivridis E, Koukourakis MI, Zois CE, Ledaki I, Ferguson DJ, Harris AL, et al. LC3A-positive light microscopy detected patterns of autophagy and prognosis in operable breast carcinomas. Am J Pathol. 2010;176:2477-89.

38. Chen S, Jiang YZ, Huang L, Zhou RJ, Yu KD, Liu Y, et al. The residual tumor autophagy marker LC3B serves as a prognostic marker in local advanced breast cancer after neoadjuvant chemotherapy. Clin Cancer Res. 2013;19:6853-62.

39. Zhao H, Yang M, Zhao J, Wang J, Zhang Y, Zhang Q. High expression of $\mathrm{LC} 3 \mathrm{~B}$ is associated with progression and poor outcome in triple-negative breast cancer. Med Oncol. 2013;30:475.

40. Liao W, Sun L, Wang C, Huang H, Liu J, Liao W, et al. LC3A-positive "stonelike" structures predict an adverse prognosis of gastric cancer. Anat Rec (Hoboken). 2014;297:653-62.

41. Charafe-Jauffret E, Tarpin C, Bardou VJ, Bertucci F, Ginestier C, Braud AC, et al. Immunophenotypic analysis of inflammatory breast cancers: identification of an 'inflammatory signature'. J Pathol. 2004;202:265-73.

42. Budczies J, Klauschen F, Sinn BV, Gyorffy B, Schmitt WD, Darb-Esfahani S, et al. Cutoff finder: a comprehensive and straightforward web application enabling rapid biomarker cutoff optimization. PLoS One. 2012;7:e51862.

43. Zengel P, Assmann G, Mollenhauer M, Jung A, Sotlar K, Kirchner T, et al. Cancer of unknown primary originating from oropharyngeal carcinomas are strongly correlated to HPV positivity. Virchows Arch. 2012;461:283-90.

44. Choi JH, Cho YS, Ko YH, Hong SU, Park JH, Lee MA. Absence of autophagyrelated proteins expression is associated with poor prognosis in patients with colorectal adenocarcinoma. Gastroenterol Res Pract. 2014:2014:179586.

45. Giatromanolaki A, Sivridis E, Mendrinos S, Koutsopoulos AV, Koukourakis MI. Autophagy proteins in prostate cancer: relation with anaerobic metabolism and Gleason score. Urol Oncol. 2014;32:39 e11-8.

46. Winardi $\mathrm{D}$, Tsai HP, Chai CY, Chung CL, Loh JK, Chen YH, et al. Correlation of altered expression of the autophagy marker LC3B with poor prognosis in astrocytoma. Biomed Res Int. 2014;2014:723176.

47. Wu DH, Jia CC, Chen J, Lin ZX, Ruan DY, Li X, et al. Autophagic LC3B overexpression correlates with malignant progression and predicts a poor prognosis in hepatocellular carcinoma. Tumour Biol. 2014;35:12225-33.

48. El-Mashed S, O'Donovan TR, Kay EW, Abdallah AR, Cathcart MC, O'Sullivan J, et al. LC3B globular structures correlate with survival in esophageal adenocarcinoma. BMC Cancer. 2015;15:582.
49. Yang Z, Ghoorun RA, Fan X, Wu P, Bai Y, Li J, et al. High expression of Beclin-1 predicts favorable prognosis for patients with colorectal cancer. Clin Res Hepatol Gastroenterol. 2015;39:98-106.

50. Chen HI, Tsai HP, Chen YT, Tsao SC, Chai CY. Autophagy and Apoptosis Play Opposing Roles in Overall Survival of Esophageal Squamous Cell Carcinoma. Pathol Oncol Res. 2016;22:699-705.

51. Fakhry C, Zhang Q, Nguyen-Tan PF, Rosenthal DI, Weber RS, Lambert L, et al. Development and validation of nomograms predictive of overall and progression-free survival in patients with oropharyngeal Cancer. J Clin Oncol. 2017;35:4057-65.

52. Peng W, Du T, Zhang Z, Du F, Jin J, Gong A. Knockdown of autophagy-related gene LC3 enhances the sensitivity of HepG2 cells to epirubicin. Exp Ther Med. 2015:9:1271-6.

53. Abedin MJ, Wang D, McDonnell MA, Lehmann U, Kelekar A. Autophagy delays apoptotic death in breast cancer cells following DNA damage. Cell Death Differ. 2007;14:500-10

54. Li J, Hou N, Faried A, Tsutsumi S, Takeuchi T, Kuwano H. Inhibition of autophagy by 3-MA enhances the effect of 5-FU-induced apoptosis in colon cancer cells. Ann Surg Oncol. 2009;16:761-71.

55. Schoenlein PV, Periyasamy-Thandavan S, Samaddar JS, Jackson WH, Barrett JT. Autophagy facilitates the progression of ERalpha-positive breast cancer cells to antiestrogen resistance. Autophagy. 2009;5:400-3.

56. Vazquez-Martin A, Oliveras-Ferraros C, Menendez JA. Autophagy facilitates the development of breast cancer resistance to the anti-HER2 monoclonal antibody trastuzumab. PLoS One. 2009;:4:e6251.

57. Claerhout S, Verschooten L, Van Kelst S, De Vos R, Proby C, Agostinis P, et al. Concomitant inhibition of AKT and autophagy is required for efficient cisplatin-induced apoptosis of metastatic skin carcinoma. Int Cancer. 2010;127:2790-803.

58. Liu D, Yang Y, Liu Q, Wang J. Inhibition of autophagy by 3-MA potentiates cisplatin-induced apoptosis in esophageal squamous cell carcinoma cells. Med Oncol. 2011;28:105-11.

59. Sasaki K, Tsuno NH, Sunami E, Tsurita G, Kawai K, Okaji Y, et al. Chloroquine potentiates the anti-cancer effect of 5-fluorouracil on colon cancer cells. BMC Cancer. 2010;10:370.

60. Sasaki K, Tsuno NH, Sunami E, Kawai K, Hongo K, Hiyoshi M, et al. Resistance of colon cancer to 5 -fluorouracil may be overcome by combination with chloroquine, an in vivo study. Anti-Cancer Drugs. 2012;23:675-82.

61. Liu JT, Li WC, Gao S, Wang F, Li XQ, Yu HQ, et al. Autophagy inhibition overcomes the antagonistic effect between Gefitinib and cisplatin in epidermal growth factor receptor mutant non-small-cell lung Cancer cells. Clin Lung Cancer. 2015;16:e55-66.

62. Liu S, Li X. Autophagy inhibition enhances sensitivity of endometrial carcinoma cells to paclitaxel. Int J Oncol. 2015;46:2399-408.

63. Zhao XG, Sun RJ, Yang XY, Liu DY, Lei DP, Jin T, et al. Chloroquineenhanced efficacy of cisplatin in the treatment of hypopharyngeal carcinoma in xenograft mice. PLoS One. 2015;10:e0126147.

64. Qin L, Xu T, Xia L, Wang X, Zhang X, Zhang X, et al. Chloroquine enhances the efficacy of cisplatin by suppressing autophagy in human adrenocortical carcinoma treatment. Drug Des Devel Ther. 2016;10:1035-45.

65. Steinman RM, Mellman IS, Muller WA, Cohn ZA. Endocytosis and the recycling of plasma membrane. J Cell Biol. 1983;96:1-27.

66. Apel A, Herr I, Schwarz H, Rodemann HP, Mayer A. Blocked autophagy sensitizes resistant carcinoma cells to radiation therapy. Cancer Res. 2008;68:1485-94.

67. Lomonaco SL, Finniss S, Xiang C, Decarvalho A, Umansky F, Kalkanis SN, et al. The induction of autophagy by gamma-radiation contributes to the radioresistance of glioma stem cells. Int J Cancer. 2009;125:717-22.

68. He G, Wang Y, Pang X, Zhang B. Inhibition of autophagy induced by TSA sensitizes colon cancer cell to radiation. Tumour Biol. 2014:35:1003-11.

69. Schonewolf CA, Mehta M, Schiff D, Wu H, Haffty BG, Karantza V, et al. Autophagy inhibition by chloroquine sensitizes HT-29 colorectal cancer cells to concurrent chemoradiation. World J Gastrointest Oncol. 2014;6:74-82.

70. Wu SY, Liu YW, Wang YK, Lin TH, Li YZ, Chen SH, et al. lonizing radiation induces autophagy in human oral squamous cell carcinoma. J BUON. 2014;19:137-44.

71. Laimer K, Spizzo G, Gastl G, Obrist P, Brunhuber T, Fong D, et al. High EGFR expression predicts poor prognosis in patients with squamous cell carcinoma of the oral cavity and oropharynx: a TMA-based immunohistochemical analysis. Oral Oncol. 2007;43:193-8.

72. Spector ME, Gallagher KK, Light E, Ibrahim M, Chanowski EJ, Moyer JS, et al. Matted nodes: poor prognostic marker in oropharyngeal 
squamous cell carcinoma independent of HPV and EGFR status. Head Neck. 2012;34:1727-33.

73. Soba E, Budihna M, Smid L, Gale N, Lesnicar H, Zakotnik B, et al. Prognostic value of some tumor markers in unresectable stage IV oropharyngeal

carcinoma patients treated with concomitant radiochemotherapy. Radiol Oncol. 2015:49:365-70.

Ready to submit your research? Choose BMC and benefit from:

- fast, convenient online submission

- thorough peer review by experienced researchers in your field

- rapid publication on acceptance

- support for research data, including large and complex data types

- gold Open Access which fosters wider collaboration and increased citations

- maximum visibility for your research: over $100 \mathrm{M}$ website views per year 